\title{
Trend of Climate Migration and Countermeasure Analysis in the Context of Climate Change Risk
}

\author{
Zhijie Cao \\ Hohai University \\ Nanjing, China \\ caozhijiehh@163.com
}

\author{
Shaojun Chen \\ The National Research Center for Resettlement \\ Hohai University \\ Nanjing, China \\ shaojun_chen@126.com
}

\begin{abstract}
In the overall context of global climate change, global warming, melting glaciers further have increased the probability of occurrence such as a gradient with a slow onset of climate risk and drought, floods and other extreme mutation catastrophic climate risk, These adverse effects has brought about a large number of really or potential climate migration, which has become a challenge of the human society in 21st century. In order to grasp the evolution trend of increasing complexity development with the climate migration climbed, affected areas continue to expand, temporary migration to permanent migration continued evolution, a variety of factors under the migration problem superposition interweave climate is become more and more complicated and attention and solve problems of perspective. And climate of the migration situation and development trend, proposes making international climate migration law, strengthen the international cooperation, to slow down and adapt to the international community, and to establish the policy and governance mechanism and management institution, reduce climate migrants' social vulnerability and other measures.
\end{abstract}

Keywords- climate change; climate risk; climate migration;presents situation; the countermeasures and proposals

\section{INTRODUCTION}

Climate change issues and actually or potentially substantial climate migration arising from climate change and its adverse impacts have become severe challenges facing human society in the 21 st century, and are among the core concerns of human society today. While climate change problems are increasingly complex, population migration arising from climate change risk, humanitarian crises, refugee floods, regional conflicts, etc. triggered by climate migration are drawing increasing attention from national governments and international society. Since Ravenstein regarded "inappropriate climate" as one of the key factors leading to population migration [1], studies on climate migration experienced twists and turns. It was not until the early 1990 s when the threat of global climate change to mankind became severe that the forecast of climate migration by Myers et al had not been realized gradually by people [2]. However, the study of Myers, Ellen Churchill Semple, Henry S, Barrios S et al on climate migration focused on future-oriented warning forecast, as well as types, scales and causes of climate migration [3], explorations on relevant problems and measures appear on the press only and seem relatively weak [4]. How to improve people's understanding of the severity of climate migration problems arising from climatic risks based on existing studies, explore and sort out crucial issues involving climate migration, and analyze restrictive factors contributing to climate migration is already an inevitable and urgent topic facing mankind.

\section{CURRENT SITUATION AND TREND OF CLIMATE MIGRATION}

"As early as the early 1990s, the global society noticed connections of migration issues with climate change and environmental deterioration. In recent years, with the increase of the certainty of global warming and the rise of the seal level, population migration issues arising from frequent environmental deterioration and extreme, sudden climate risk events have made 'climate migrants' a new global focus" [5]. As estimated by parties concerned, there are already about 30 million climate migrants in the world and this number will rise dramatically to 50 million by 2020 and 200 million by 2050 .Climate migration problems are increasingly drawing the attention of organizations concerned, governmental agencies and researchers. However, since no international cooperative mechanism has been established to handle climate migration issues to date, topics on climate migration have not been addressed properly, and things may become even worse.

\section{A. Population of climate migration keeps rising}

Due to global climate change (significant rise of air temperature, change in rainfall and monsoons, sea level rise, glacier melting, droughts, floods, stronger tropical cyclones, sandstorms, hurricanes, snows, etc.) and natural disasters, climatic disasters are rising in quantity and magnitude, resulting in the expansion of climate migration directly. Climatic risks have become the main cause of migration in the 21st century. According to reports published by the United Nations Environment Programme, and Oxfam Hong Kong - a Hong Kong development and relief NGO, the number of climate refugees affected by climatic disasters worldwide per annum during 1998-2007 was about 243 million, and will exceed 375 million after 2015. Today, climate refugees in many countries and 
regions are undergoing voluntary and organized climate migration. The global population of climate migration has reached about 26 million, and is expected to reach 200 million by 2050 [6].

\section{B. Areas affected by climate migration are expanding}

The change of the human living environment arising from climate change and human activity has made some countries and regions no longer suitable for human survival and habitation (e.g., sea level rise will render some countries and regions submerged). According to the expected evolution pattern of climatic risks, more and more countries and regions in the world will become unsuitable for human habitation. Climate migrants have to look for opportunities of survival and development from country to country or from region to region under the high pressure of climatic risks. Currently, areas affected by climate migration are obviously expanding. The World Bank, International Organization for Migration, Asian Development Bank, and other international organizations predict based on major climatic risks that have occurred that in the next 20-50 years, hot regions of global climate migration will be low-lying coastal regions and estuary deltas in East Asia, South Asia, East Africa, Central Africa and Central America, low-lying small Pacific island countries, and semi-dry regions [7].

\section{Continuous evolution from temporary relocation to permanent migration}

Climate migration is or is about to experience the tough transition from temporary relocation to permanent migration. Climate migrants live in underdeveloped regions with relatively harsh natural conditions mainly. Due to the lack of resources for relocation, people are usually relocated to take shelter when they are hit by disasters like typhoons, rainstorms, floods, droughts, mudrock flows or sudden epidemics. However, as climatic risks become normalized in a certain region, permanent relocation will become an inevitable choice. For example, the Xihaigu region with harsh climatic conditions in the Ningxia Hui Autonomous Region of China is increasingly affected by droughts and can no longer support its population. In response to this extremely dry climate, the government of the autonomous region has to relocate about 760,000 people in the central dry and southern mountainous areas permanently to areas with relatively better irrigation conditions to meet their basic survival and development needs. In the realistic background of aggravating climatic risks, global warming and sea level rise have rendered some low-lying inundated, and many countries and regions are conducting permanent climate migration. For example, more and more climate migrants in Bangladesh are migrating from low-lying coastal regions to inland cities and neighboring countries like India, and nearly 400,000 residents in resort paradise island Maldives have to take shelter elsewhere [4]61.

\section{Multiple factors work together to make climate migration increasingly complex}

As more extreme climate events arise from global climate change, "climate migration" arising from climatic risks will be accelerated in the next few decades, and climate migration problems will become more complex. First, climate migration will further aggravate social conflicts and tensions in relevant countries, and natural disasters arising from climatic risks will force some victims to swam into big cities, increasing the population, resource and environmental pressure of big cities, worsen the current situation, and aggravate destabilizing factors. Second, climate migration problems will threaten weak relations among countries and regions at the brink of conflict. In regions with intensive climate migration and their border areas, the probability of the vicious cycle of climate change $\rightarrow$ environmental deterioration $\rightarrow$ climate migration $\rightarrow$ social conflict will rise, thereby giving rise to ethnic problems, religious conflicts and destabilizing factors. Third, the poverty issue of climate migrants is interwoven with environmental deterioration, making things more complex. In regions where poverty and natural conditions deteriorate seriously, secondary disasters arising from "climatic poverty" are very likely to occur.

\section{COUNTERMEASURES TO CLIMATE MIGRATION PROBLEMS}

In the foreseeable future, extreme climate events will be more frequent, and climate change and natural disasters will become another drive to population migration, and climatic risks will be a main cause of global population migration in the 21 st century. Since increasingly urgent climate migration problems are closely associated with social reality, susceptible countries and regions must take more extensive actions to respond to climate migration immediately, and establish effective adaptation mechanisms at the regional, national and international levels to minimize adverse impacts of climate migration on global sustainable development in the future.

\section{A. Improving provisions on "refugee" rights in prevailing international laws, and developing laws on international climate migration}

Since involuntary climate migration has not been included international refugee and migration policies, climate migration has not been recognized explicitly by applicable international laws both politically and legally [8]. Increasingly urgent realistic climate migration problems are seriously disengaged with laws and regulations, and climate migrants are not legally protected in international society. As a result, the 1951 Refugee Convention should be amended or a separate convention on climate migration drafted separately to respond to climate migration problems arising from climate change, and provide humanitarian assistance to climate migrants. In addition, international laws on climate migration should be enacted on the basis of the United Nations Framework Convention on Climate Change to stipulate responsibilities of international organizations and national governments in climate migration, define basic guidelines and principles for responding to climate migration, establish mechanisms for international cooperation and domestic coordination, give full play to the dominant role of international organizations and national governments in climate migration, and address climate migration problems timely. In addition, when environmental deterioration events and sudden disasters arise from climatic risks, the principle of human rights non-rejection should be taken into account in international laws. 
B. Strengthening international cooperation to promote the establishment and improvement of inter-regional collaboration mechanisms, and solve climate migration problems effectively

Climate migration is a global issue, and may impose new challenges on international society in such fields as politics, diplomacy, economic and social development, and cooperation on environmental change. All countries in the world should join hands to address climate migration problems by strengthening capacity building and improving relevant mechanisms. First, population migration arising from climate change should be included in international plans of national governments in response to climate change, and made part of national actions; exchange mechanisms for officials and experts of member countries should be established to drive international cooperation on climate migration. Second, ethical and incentive mechanisms for the gratuitous acceptance of climate migrants may be established worldwide, and international society should be advocated to provide donations and assistance to migrants suffering extreme climate events. Third, the international migration management system composed mainly of international management organizations should be improved, and existing international development and cooperation mechanisms (e.g., South-South Cooperation, regional economic and trade cooperative organizations, and international financial institutions) fully utilized to improve the adaptability of developing countries, and reduce climatic risks [4].

\section{Establishing policies, governance mechanisms and administrative organizations for responding to climate migration flexibly in international society}

Currently, climate migration is not taken into account in policies for both origin and target places, and there is no uniform administrative organization to handle climate migration affairs in international society. It is an urgent task to convene internationally authoritative organizations in migration research to develop globally authoritative provisions on climate migration, define the authorities and responsibilities of international migration organizations and the Office of the UN High Commissioner for Refugees, develop relevant policies, administrative organizations, institutions and governance mechanisms. First, a set of social management and governance mechanisms for responding to climate migration flexibly may be established in international society. Second, disaster prediction and early warning mechanisms on climate change should be established. Third, monitoring and evaluation on climate migration should be strengthened based on the knowledge that prevention is better than control.

\section{Paying equal attention to mitigation and active adaptation to reduce the social risk of passive climate migration}

The trend of global warming is inevitable, and climatic risks are rising in quantity and magnitude. In the next few decades, even the best mitigation efforts are made, further impacts of climate change cannot be avoided, so that mitigating and actively adapting to climate migration problems has become the only feasible and appropriate solution. Mitigation and adaptation measures that can be taken include constructing flood banks, reservoirs, etc. to respond to potential climate migration arising from floods, droughts and other disasters, offering universal education on knowledge on climatic risks to strengthen people's understanding of climate change, its impacts and countermeasures, and guiding population migration rationally to reduce impacts of blind migration on economic and social development, and urban life.

\section{E. Reducing the social vulnerability of climate migrants and improving their adaptability to weaken impacts of climatic risks}

In different regions with different social institutions, different groups or even families differ greatly in social vulnerability, where vulnerable or marginal groups are more likely to suffer from disasters. If mankind cannot stop global climate change, people can at least manage to enhance social tolerance and reduce social vulnerability in face of factors that may lead to migrating other than always choosing migration. This requires people to draw on social vulnerability theory and migrate to nearby developed areas where possible to increase the social tolerance of migrants when choosing climate migration areas; so that the social vulnerability of migrants is not increased due to relocation and potential risks are left over for future development, such as migrant reflux. On the other hand, existing adaptation funding mechanisms should be improved, and climate migration funds or financing systems established to provide financial and technical support to poor areas, and reduce the social vulnerability of high-risk areas.

\section{SUMMARY}

In the context of global climate change, main symptoms of climate change - gradual and sudden climatic risks - are increasingly unpredictable, the probability of climatic risks is rising, and resulting climate migration problems are increasingly complex and sensitive to solve. Climate migrants are faced with both the urgent food and habitat problem, and the problem of how to adjust their means of livelihood, and realize cultural and personal identification in the new natural and cultural environment of the destination. Due to extensive global impacts of climate change, climate migrants spread all over the world, and are faced with a series of social, economic, political, cultural, environmental, resource, mental, ecological and administrative issues associated with climate migration. It is not only the responsibility of any certain country or several countries to address these issues, but the whole of mankind should assume and face this task together, and address these issues through active and effective consultation. However, since no international cooperation mechanism has been established to address climate migration issues, the situation may become even worse. Climate migration should be taken into account in policies, uniform administrative organizations established in international society to manage climate migration affairs, a global monitoring and evaluation mechanism on climate migration established, and appropriate policies and management institutions on climate migration developed in order to prepare statistics and predictions on climate 
migration, enact policies and perform national management.

\section{ACKNOWLEDGMENT}

This article was prepared under the Foundation project: "Minority Involuntary Hydropower Resettlement Social and Cultural Adaptation Research" (No.: 14CSH047) and the "Discipline Cross Resettlement Project Research" (No.: $13 \& Z D 172)$ were supported by the National Social Science Fund of China; Also supported by the China Postdoctoral Science Foundation (No.: 2014M561563), the Fundamental Research Funds for the Central Universities (No.: 2014B09814)", and is an interim output thereof.

\section{REFERENCES}

[1] Ravenstein E G. The Laws of Migration[J]. Journal of the Royal Statistical Society, 1889, 52(2): 241-305.
[2] Myers N. Environmental Refugees: An Emergent Security Issue [C]. 13th ed Economic Forum, Prague, 2005, 5:73-79.

[3] Castles S. Environmental Change and Forced Migration: Making Sense of the Debate [J]. New Issues in Refugee Research UNHCR Research Paper, 2002:70.

[4] Pan Jiahua, ZhengYan, BoXu. Sounded New Warning: Climate Immigration [J]. The World Knowledge, 2011(9) : 61-62.

[5] Cao Zhijie, Chen Shaojun. Migration Mechanism of Climate Migrants and Analysis of Relevant Concepts, J. EI. Advanced Materials Research Vols.518-523 (2012): 5070-5074.

[6] Li Jifeng. Forced Migration of the Climate Refugees [N]. Literature Report, 2010-01-07(8).]

[7] Pan Jiahua, Zheng Yan. Climate Change Hasten Parturition Immigration Asia Pacific has been a Hot Topic Area[N]. WenHui Newspapers, 2011-05-27(2)

[8] FOE, Melbourne. A Citizen's Guide to Climate Refugees[C].Friends of the Earth, Australia, 2005:226-241. 